\title{
Modified Theoretical Expression of Water Saturation in Oil-Water Fluid Flow Area
}

\author{
H.H. Liu ${ }^{*}$
}

Department of Computer Engineering, Sichuan College of Architectural Technology, Chengdu, China

\begin{abstract}
Theoretical study of water saturation in oil-water fluid flow area is meaningful to the high, stabilized production and the improvement of ultimate recovery. Combining relational expression between relative permeability and water saturation with the fractional flow equation produced an expression of water cut changed by water saturation; Introducing Vieta's theorem to the differentiation of water cut gave a theoretical expression of water saturation in oil-water fluid flow area; Introducing the concept of frontal water saturation to these expressions give the continuous expression of water saturation. Applying this formula to certain sandstone reservoir in China achieves good results: In oil-water seepage process, water saturation is increasing by frontal distance, and the frontal distance increases over time. This new water saturation equation lays a base for the study of residual oil mobility and enhanced oil recovery.
\end{abstract}

Keywords: Relative permeability, percolation mechanics, Buckley-Leverett equation, Vieta's Theorem, frontal water saturation.

\section{INTRODUCTION}

Buckley-Leverett (1942) proposed the Buckley-Leverett equation [1], but we cannot deduce the theoretical expression of water saturation from it. Since then, many scholars began to study the water saturation and already made some progress. The previous study was based on the experimental method, Archie (1942) established a formula of water saturation adaptive to these pure sandstone reservoirs [2]; Poupon's work (1971)[3] was based on Simandoux's which was done in 1983 [4], where an equation of water saturation was given. Fertl (1982) [5] and Dewan (1998) [6] further developed the above-mentioned equation. Yao (1993) et al. used the analytical forecasting method to study the water saturation of reservoir [7]; Zhang et al. (2008) theoretically deduced the relation between electric resistivity and water saturation [8]; Wang et al. (2010) [9] and Li (2010) [10] also studied the water saturation of oil reservoirs with the experimental method, respectively. However, there is seldom theoretical research on water saturation based on the percolation mechanics method. In this paper, we aim to propose a new theoretical expression of water saturation based on percolation mechanics.

\section{ASSUMPTIONS}

(1) Oil-water fluid flow;

(2) Homogeneous porous media;

(3) Incompressible rock and liquid;

(4) Obey the Darcy's law;

(5) Satisfy the 1D Buckley-Leverett equation;

(6) Follow the law of conservation of mass;

*Address correspondence to this author at the Department of Computer Engineering, Sichuan College of Architectural Technology, Chengdu, China; Tel: 15882401908; Fax: 83037760; Email: Tsinghua616@163.com

\section{QUANTITATIVE DESCRIPTION OF WATER SATURATION}

Quantitative description of water saturation

$$
\begin{aligned}
& \text { He, G.S's work (1994) [11] refers } \\
& \frac{k_{o}}{k_{w}}=a e^{-b S_{w}}
\end{aligned}
$$

By introducing Eq. (1) to the fractional flow equation gives

$$
f_{w}=\frac{1}{1+M a e^{-b S_{w}}}
$$

Where coefficients $a, b$ are determined by properties of rock and fluid and can be solved by graphical method.

The Buckley-Leverett equation is a transport equation used to model two-phase flow in porous media. The Buckley-Leverett equation or the Buckley-Leverett displacement can be interpreted as a way of incorporating the microscopic effects to due capillary pressure in two-phase flow into Darcy's law. In a 1D sample (control volume), let $S_{w}$ be the water saturation, then the Buckley-Leverett equation is

$$
\frac{d x}{d t}=\frac{q(t)}{\phi A} \frac{d f_{w}}{d S_{w}}
$$

Introducing integration to Eq. (3) gives

$$
\frac{\phi A}{W(t)}\left(x-x_{0}\right)=f_{w}^{\prime}\left(S_{w}\right)
$$

When $x=x_{0}$ (initial place of oil-water seepage flow area), $S_{w}=1-S_{o r}$. 
Introducing the differentiation of Eq. (2) to Eq. (4) gives

$$
\frac{\phi A}{W(t)}\left(x-x_{0}\right)\left(1+M a e^{-b S_{*}}\right)^{2}=M a b e^{-b S_{\nu}}
$$

By setting $y=e^{-b S_{v}}$ in Eq. (5) gives

$\frac{\phi A}{W(t)}\left(x-x_{0}\right) M^{2} a^{2} y^{2}+\left(2 M a \frac{\phi A}{W(t)}\left(x-x_{0}\right)-M a b\right) y+\frac{\phi A}{W(t)}\left(x-x_{0}\right)=0$

Let

$\frac{\phi A}{W(t)}\left(x-x_{0}\right) M^{2} a^{2}=A_{1}, 2 M a \frac{\phi A}{W(t)}\left(x-x_{0}\right)-M a b=A_{2}, \frac{\phi A}{W(t)}\left(x-x_{0}\right)=A_{3}$

produces a quadratic equation $A_{1} y^{2}+A_{2} y+A_{3}=0$.

Solving the quadratic equation and taking the natural logarithm gives [12]

$$
\begin{aligned}
& S_{w}=\frac{1}{b} \ln \left(\frac{2 \phi A\left(x-x_{0}\right) M a}{-\left[2 \phi A\left(x-x_{0}\right)-b W(t)\right]+W(t) \sqrt{b\left[b-\frac{4 \phi A}{W(t)}\left(x-x_{0}\right)\right]}}\right), 0<x-x_{0}<\frac{b W(t)}{4 \phi A} \\
& S_{w}=\frac{1}{b} \ln \left(\frac{2 \phi A\left(x-x_{0}\right) M a}{-\left[2 \phi A\left(x-x_{0}\right)-b W(t)\right]-W(t) \sqrt{b\left[b-\frac{4 \phi A}{W(t)}\left(x-x_{0}\right)\right]}}\right), 0<x-x_{0}<\frac{b W(t)}{4 \phi A}
\end{aligned}
$$

When $x=x_{0}+\frac{b W(t)}{4 \phi A}$, Eq. (7) and Eq. (8) gives $S_{w}=\frac{\ln (M a)}{b}$.

Here, $x_{f}=x_{0}+\frac{b W(t)}{4 \phi A}$ is the location of frontal zone in time $t$. This formula shows that the location of frontal zone goes forward with the increase of oil production, and the water saturation $S_{w f}=\frac{\ln (M a)}{b}$ should be frontal water saturation.

Introducing the inequality $S_{w f} \geq S_{w} \geq 0$ (instead of $1 \geq S_{w} \geq 0$ ) to Eq. (7) gives $\frac{b W(t)}{2 \phi A(M a+1)} \leq x-x_{0} \leq \frac{b W(t)}{4 \phi A}$.
Hence, the distribution equation of water saturation becomes:

$S_{u}=\frac{1}{b} \ln \left(2 \phi A\left(x-x_{0}\right) M a /-\left[2 \phi A\left(x-x_{0}\right)-b W(t)\right]+W(t) \sqrt{b\left[b-\frac{4 \phi A}{W(t)}\left(x-x_{0}\right)\right]}\right), \frac{b W(t)}{2 \phi A(M a+1)} \leq x-x_{0} \leq \frac{b W(t)}{4 \phi A}$

Introducing the inequality $S_{w f} \geq S_{w} \geq 0$ (instead of $1 \geq S_{w} \geq 0$ ) to Eq. (8) gives no solution, hence the distribution equation of water saturation is eq. (9). Here, the inequality $S_{v f} \geq S_{v} \geq 0$ is the guarantee of single value of water saturation.

Note: the above-mentioned deduction of water saturation shows: the function of water saturation is continuous in interval $\left[\frac{b W(t)}{2 \phi A(M a+1)}, \frac{b W(t)}{4 \phi A}\right]$, and this water saturation distribution equation is adaptive to any water driving oil reservoir.

\section{APPLICATION AND DISCUSSION}

Given the water and oil permeability and practical development data of certain sandstone oil reservoir, see (Table 1 and Table 2).

By using graphical method gives $a=22.39, b=1.52$ and the theoretical expressions:

$S_{w}=\frac{1}{1.52} \ln \frac{1880.8\left(x-x_{0}\right)}{45.6 t-420\left(x-x_{0}\right)+30 t \sqrt{\left.2.3104-\frac{42.56\left(x-x_{0}\right)}{t}\right]}}, 0.01982 t \leq x-x_{0} \leq 0.0543 t$

After fixing the producing time to $100,200,300,400$, 500, 600days (Ds) gives (Fig. 1).

Fig. (1) shows that, in oil and water seepage area, water saturation is increasing by frontal distance, and the frontal distance increases over time. When fixing the producing time from 100 days to 600 days, the distribution curve water saturation changed after producing for 500 days, compared to the 400 days producing time.

\section{CONCLUSION}

1. Modified theoretical expression of water saturation based on reference [12] in oil-water fluid flow area is established.

2. In oil-water seepage process, water saturation is increasing by frontal distance, and the frontal distance increases over time.

Table 1. Water and Oil Permeability Data of a Sandstone Oil Reservoir

\begin{tabular}{|c|c|c|c|c|c|c|c|c|c|c|c|c|}
\hline$S_{w}, \%$ & 0 & 10 & 20 & 30 & 40 & 50 & 60 & 70 & 75 & 80 & 90 & 100 \\
\hline$K_{r o}$ & 1 & 1 & 1 & 0.94 & 0.80 & 0.44 & 0.16 & 0.045 & 0 & 0 & 0 \\
\hline$K_{r w}$ & 0 & 0 & 0 & 0 & 0.04 & 0.11 & 0.20 & 0.30 & 0.36 & 0.44 & 0.68 & 1 \\
\hline
\end{tabular}

Table 2. Practical Development Data of a Sandstone Oil Reservoir

\begin{tabular}{|c|c|c|c|c|c|}
\hline $\begin{array}{c}\text { Velocity Ratio of Oil and } \\
\text { Water }\end{array}$ & Porosity & $\begin{array}{c}\text { Reservoir } \\
\text { Width, } \mathbf{m}\end{array}$ & $\begin{array}{c}\text { Formation } \\
\text { Thickness, } \mathbf{m}\end{array}$ & Single Well Production, $m^{3} / d$ & $\begin{array}{c}\text { Residual Oil } \\
\text { Saturation }\end{array}$ \\
\hline \hline 5 & 0.25 & 140 & $6 \mathrm{~m}$ & 30 & 0.32 \\
\hline
\end{tabular}




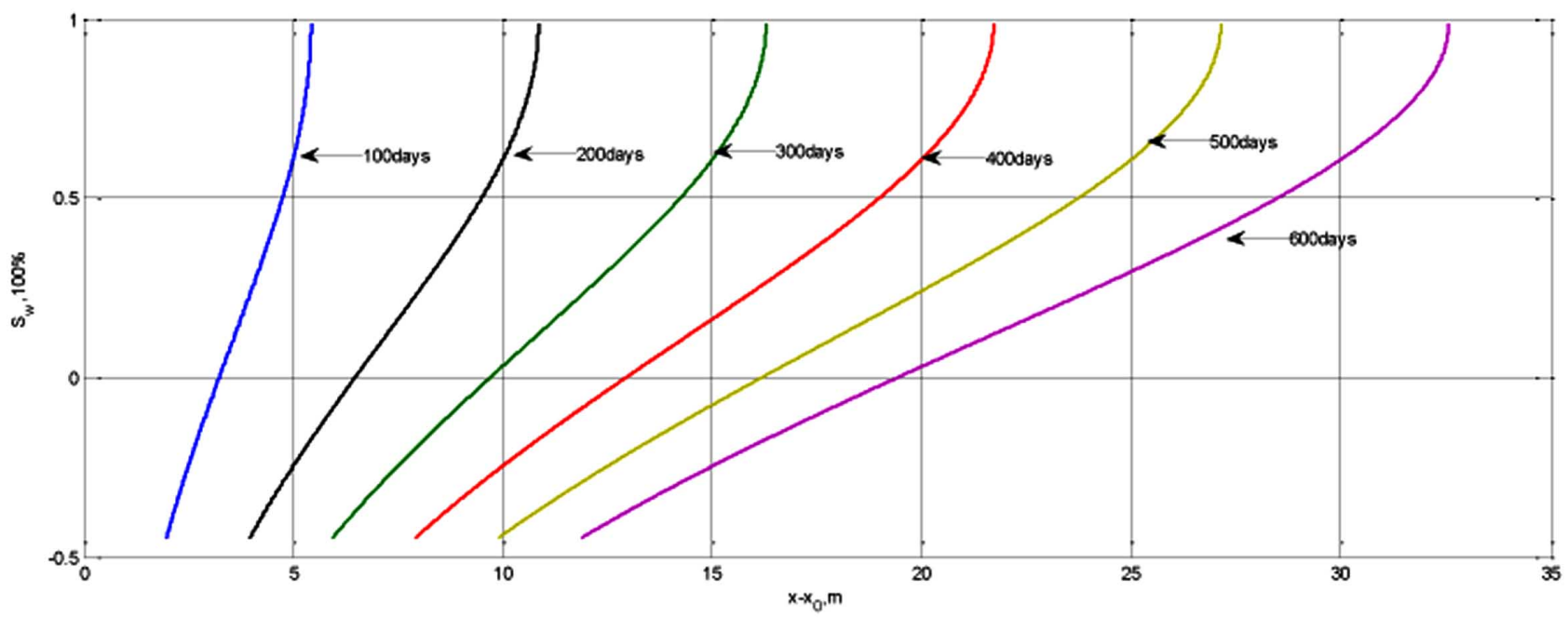

Fig. (1). Distribution of water saturation in 100Ds.

\section{CONFLICT OF INTEREST}

The author(s) confirm that this article content has no conflicts of interest.

\section{ACKNOWLEDGEMENT}

I would like to acknowledge reviewers and the editor for their many helpful comments and suggestions that improved the manuscript significantly.

\section{NOMENCLATURE}

$$
\begin{array}{ll}
k_{o} & =\text { Oleic permeability } \\
k_{w} & =\text { Water phase permeability } \\
a & =\text { Linear intercept } \\
b & =\text { Linear slope } \\
f_{w} & =\text { Water cut or fractional flow rate } \\
M & =\text { Viscosity ratio of water and oil } \\
\phi & =\text { Porosity } \\
A & =\text { Seepage flow area } \\
S_{o r} & =\text { Residual oil saturation } \\
S_{w r} & =\text { Irreducible water saturation } \\
x_{f} & =\text { Location of frontal zone in time } t \\
\partial f_{w} / \partial S_{w} & =\text { Ratio of change in water cut to change in satu- } \\
& \quad \text { ration } \\
x-x_{0} & =\text { Forwarding distance of any constant water } \\
& \quad \text { saturation in seepage area }
\end{array}
$$

$W(t)=$ Total water injection from the beginning time to $t$

\section{REFERENCES}

[1] S.E. Buckley, and M.C. Leverett, "Mechanism of fluid displacements in sands", Transactions of the AIME vol. 146, pp. 107-116, 1942 .

[2] G.E. Archie, "The electrical resistivity log as an aid in determining some reservoir characteristics", Petroleum Transactions of AIME, vol. 146, pp. 54-62, 1942.

[3] A. Poupon, M.E. Loy, and M.P. Tixier, "A contribution to electric log interpretation in shaly sands", Journal of Petroleum Technology, vol. 6, no. 6, pp. 27-34, 1954.

[4] P. Simandoux, "Dielectric measurements of porous media: Application to measurement of water saturations-study of the behavior of argillaceous formations", Oil \& Gas Science and Technology, vol. 18, no. SI, pp. 193-215, 1963.

[5] W.H. Fertl, and G. W. Hammack, "A comparative look at water saturation computation in shaly pay sands", The log Analyst, vol. 23, no. 2, pp. 12-20, 1982.

[6] J. Dewan, Essential of modern open-hole log interpretation. Oklahoma: Penn Well Publishing Company, 1988.

[7] H.S. Yao, and K.L. Xiang, "Analytical forecasting for water saturation of reservoirs", Systems Engineering-Theory and Practice, vol. 3, pp. 137-142, 1993.

[8] C.M. Zhang, and Z.S. Zhang, "Study on theoretical deduction between water flooding resistance and water saturation and on numerical simulation", Science In China Press, vol. 22, no. 2, pp. 151-156, 2008.

[9] X. Wang, and T.V. Nguyen, "An experimental study of the liquid water saturation level in the cathode gas diffusion layer of a PEM fuel cell", Journal of Power Sources, vol. 197, pp. 50-56, 2012.

[10] L. Xiaoluo, and M. Liqing, "Study on calculation method of reservation water saturation by PND seizing pattern", Petroleum Instruments, vol. 3, pp. 24, 2010.

[11] G.S. He, Petroleum physics (in Chinese). Petroleum Industry Press, 247-248, 1994.

[12] Z.B. Liu, H.H. Liu, and X.F. Ding, "Theoretical study of water saturation with percolation mechanics method", The Open Petroleum Engineering Journal, vol. 5, pp. 21-25, 2012.

This is an open access article licensed under the terms of the Creative Commons Attribution Non-Commercial License (http://creativecommons.org/licenses/by-nc/3.0/) which permits unrestricted, non-commercial use, distribution and reproduction in any medium, provided the work is properly cited. 